\title{
Preventative effects of fermented Chimonobambusa quadrangularis shoot on activated carbon-induced constipation
}

\author{
GUIJIE LI ${ }^{1-5^{*}}$, XIAOCHUAN ZOU ${ }^{1-4^{*}}$, GANG KUANG ${ }^{1-4}$, YANRONG REN $^{1-4}$, \\ CHAOFANG DENG ${ }^{1-4}$, QIANG LIN ${ }^{1-4}$, XIN ZHAO ${ }^{1-4}$, SONG XU $^{6}$ and JIA-LE SONG ${ }^{1,7}$ \\ ${ }^{1}$ Chongqing Collaborative Innovation Center for Functional Food; ${ }^{2}$ Chongqing Engineering Research Center of \\ Functional Food; ${ }^{3}$ Chongqing Engineering Laboratory for Research and Development of Functional Food; \\ ${ }^{4}$ Department of Biological and Chemical Engineering; ${ }^{5}$ Institute of Functional Ecological Food, Chongqing University of \\ Education, Chongqing 400067; ${ }^{6}$ Chongqing Xuerui Shengquan Agricultural Development Co., Ltd., Chongqing 400802; \\ ${ }^{7}$ Department of Nutrition and Food Hygiene, School of Public Health, \\ Gulin Medical University, Gulin, Guangxi 541004, P.R. China
}

Received May 4, 2015; Accepted July 1, 2016

DOI: 10.3892/etm.2017.4036

\begin{abstract}
The present study aimed to determine the preventative effects of fermented Chimonobambusa quadrangularis shoot (FCQS) on activated carbon constipation in Kun Ming mice. FCQS has a more loose fiber tissue structure than unfermented fresh $C$. quadrangularis shoot (CQS), which is preferable for relieving constipation. In mice fed with FCQS for 9 days the time from consumption to their first black stool defecation (117 min) was shorter than the control group (192 min) and the CQS group (148 min); however, it was longer than the normal (85 min) and bisacodyl treatment (99 min) groups. The gastrointestinal transit of the FCQS group (73.8\%) was increased, as compared with the control (37.9\%) and CQS (61.7\%) groups; however, it was decreased as compared with the normal $(100 \%)$ and bisacodyl $(88.3 \%)$ groups. By observing the hemotoxylin and eosin-stained section of mice intestine, it was demonstrated that FCQS reduced injury to the intestinal tract resulting from constipation and alleviated the damage caused to the intestinal villi over the effects observed in the CQS group. Furthermore, FCQS was also able to increase the serum levels of motilin, endothelin-1, vasoactive
\end{abstract}

Correspondence to: Professor Xin Zhao, Department of Biological and Chemical Engineering, Chongqing University of Education, 9 Xuefu Main Street, Chongqing 400067, P.R. China

E-mail: zhaoxin@cque.edu.cn

Dr Jia-Le Song, Department of Nutrition and Food Hygiene, School of Public Health, Gulin Medical University, 109 North 2nd Huan Cheng Road, Gulin, Guangxi 541004, P.R. China

E-mail: foods@live.cn

*Contributed equally

Key words: Chimonobambusa quadrangularis shoot, fermentation, constipation, activated carbon, bisacodyl intestinal peptide and acetylcholinesterase compared with the control group. c-Kit, stem cell factor (SCF), glial cell-derived neurotrophic factor (GDNF) mRNA and protein expression levels in the small intestinal cells of FCQS-fed mice were increased, as compared with CQS-fed mice. Transient receptor potential cation channel subfamily V member 1 (TRPV1) and nitric oxide synthase (NOS) expression levels of small intestinal cells of FCQS-fed mice were reduced, as compared with CQS-fed mice. These findings demonstrated that FCQS may induce improved preventative effects on constipation, compared with CQS.

\section{Introduction}

Chimonobambusa quadrangularis (Fenzi) Makino, which belongs to Gramineae Bambusoideae Chimonobambusa (1), predominantly grows in high-altitude jungles in the Southwest and its shoots are a natural, high quality food (2). Square bamboo typically matures in autumn, which is distinct from other types of bamboo. Square bamboo shoots are nutritionally-rich, including protein, fat, carbohydrate, cellulose, vitamin $\mathrm{C}$, vitamin $\mathrm{B}$ and other mineral elements such as calcium, phosphorus, iron, zinc and selenium (3). Fermentation improves the quality of the food, including its taste and the proportion of nutrients, whereas fermentation by microbes improves the physiological functions of dietary fiber in the bamboo shoots (4).

In modern society, constipation is a common physiological state, and individuals who suffer from constipation experience decreased bowel movements (5). Furthermore, the amount of defecation decreases and difficulty defecating is a result of a lack of water (6). Due to current working conditions, $\sim 70 \%$ of individuals are in a suboptimal state with stomach diseases and constipation (7). Foods that may improve these conditions include health foods (such as green tea, Korea Kimchi) and functional foods (such as soybean oligosaccharides, dietary fiber) that aid the return to normal function, and foods that improve constipation are an important and effective way to improve intestinal health (8). Fiber in bamboo shoots has been 
proven to have a good effect on inhibiting constipation (9), and it is has been reported that dietary fiber in the bamboo shoots can be improved through fermentation, and therefore its effect on constipation may also improve (10).

Activated carbon is able to reduce intestinal peristalsis and delay the pass of intestinal contents, which may lead to constipation when administered under normal conditions (11). Activated carbon has become an important experimental method of examining the effects of food on the inhibition of constipation (12). The present study adopted activated carbon to induce constipation in mice in order to observe the preventative effect of fermented bamboo shoots on constipation, which may provide support for the further development and utilization of fermented bamboo shoots as a gastrointestinal (GI) functional food.

\section{Materials and methods}

Fermentation of C. quadrangularis shoot. Cultivated Lactobacillus acidophilus (1.1854) and Streptococcus thermophilus (1.1855; both China General Microbiological Culture Collection Center, Beijing, China) were centrifuged at 3,000 x $g$ for $10 \mathrm{~min}$, after which the supernatant was discarded, washed with a moderate amount of saline, and suspended in saline in order to adjust the concentration of the bacteria liquid to $7.5 \times 10^{9} \mathrm{CFU} / \mathrm{ml}$ (L. acidophilus: S. thermophilus, 1:1). L. acidophilus and S. thermophilus were subsequently mixed to achieve $C$. quadrangularis shoot fermented bacterial liquid in the proportion of $1: 1$. Fresh C. quadrangularis shoot $(5 \mathrm{~kg})$ were washed and crumbled, and $500 \mathrm{ml}$ mixed fermented bacteria liquid was subsequently added at $42^{\circ} \mathrm{C}$ (fix format) for $16 \mathrm{~h}$ for the main fermentation step. Following this, prophase fermentation was performed at $4^{\circ} \mathrm{C}$ for $12 \mathrm{~h}$ to attain the fermented C. quadrangularis shoot.

Microscopic evaluation of the fiber in C. quadrangularis shoots. Fresh C. quadrangularis shoot (CQS) and fermented C. quadrangularis shoot (FCQS) were smashed using a grinder and washed for $10 \mathrm{~min}$ with saline three times. The liquid was discarded and $95 \%$ alcohol (10X) was added to clean the residue and the mixture was subsequently centrifuged at $750 \times g$ for $5 \mathrm{~min}$. The supernatant was discarded, the small piece of clean solid was squashed and 3 drops of $1 \%$ ethanol solution of methylene dye were prepare the slide containing $C$. quadrangularis shoot fiber. The slide was observed at x20 magnification under a microscope (Y-2A; Nikon Corp., Tokyo, Japan).

Manufacture of C. quadrangularis shoot feed. Following pasteurization, CQS and FCQS were dried, smashed and subsequently mixed with the feed at a ratio of 1:9 according to the weight prior to being pressed into a mold. These CQS and FCQS feeds were then added to the experimental mouse feed to a total of $10 \%$ CQS and FCQS.

Establishment of a mouse model of constipation. Seven-week-old female imprinting Kun Ming mice $(n=50$; weight, 25-30 g) Experimental Animal Center of Chongqing Medical University, Chongqing, China) were randomly divided into normal, control, bisacodyl treatment, SCQ and
FSCQ groups ( $n=10 /$ group). The mice were maintained in a temperature-controlled facility (temperature $23 \pm 1^{\circ} \mathrm{C}$, relative humidity $50 \pm 5 \%$ ) with a 12 -h light/dark cycle. During the experiment, mice in the normal group were not treated. Mice in the control group were not treated during the first 6 days; however, after this they were administered activated carbon water by lavage once daily for 3 days. Mice in the bisacodyl treatment group were administered bisacodyl (100 mg/kg body weight) once daily, and after 6 days were administered activated carbon water by lavage once daily without bisacodyl for 3 days. Mice in these three groups were administered water and were permitted ad libitum access to feed. Mice in the SCQ and FSCQ groups were administered feed containing 10\% SCQ and FSCQ, respectively, and ad libitum access to water during the whole experiment, and activated carbon water was administered by lavage during the final 3 days. All groups were restricted from consuming food after 9 days for $24 \mathrm{~h}$, and were administered $10 \%$ activated carbon ice water at a concentration of $0.1 \mathrm{ml} / 10 \mathrm{~g}$ by lavage. Each group was divided into two subgroups. Five mice from each group were observed to determine the time point at which they discharged their first black stool defecation, whereas the remaining five mice were euthanized by cervical vertebra dislocation $30 \mathrm{~min}$ after activated carbon water lavage to observe the GI transit of activated carbon in the small intestine. GI transit was calculated as follows: GI $(\%)=$ distance traveled by activated carbon in the small intestine/the total length of small intestine x $100 \%$ (13). These experiments followed a protocol approved by the Animal Ethics Committee of Chongqing Medical University (Chongqing, China).

Determination of serum indices. Mouse blood $(0.1 \mathrm{ml})$ was centrifuged at 3,000 x $g$ for $10 \mathrm{~min}$. The supernatant, which contained the mouse serum, was used to determine the indices of motilin (MTL), endothelin-1 (ET-1), vasoactive intestinal peptide (VIP) and acetylcholine enzyme (AchE), which were measured according to the manufacturer protocols outlined in the MTL, ET-1, VIP (Cusabio Biotech Co., Ltd., Wuhan, China) ELISA kits and AchE kit (Nanjing Jiancheng Bioengineering Institute, Nanjing, Jiangsu, China) .

Pathological observation of the small intestine. The rats were sacrificed using the cervical vertebra dislocation method. Following dissection, the small intestine was placed in $10 \%$ formalin solution for $24 \mathrm{~h}$ and $95 \%$ ethanol to dehydrate prior to xylene treatment. Transparent blocks were embedded in melted paraffin, sliced by microtome and stained with hematoxylin eosin, and observed at X10 magnification under a Nikon Y-2A microscope (14).

Reverse transcription-polymerase chain reaction (RT-PCR) analysis. Total RNA (2 $\mu \mathrm{g})$ was extracted from the small intestine using RNAzol (Invitrogen; Thermo Fisher Scientific, Inc., Carlsbad, CA, USA) reagent from the small intestine of each group. RNA concentration was adjusted to $1 \mu \mathrm{g} / \mu 1$. and $2 \mu \mathrm{l}$ RNA extracts were respectively added to $1 \mu \mathrm{l}$ oligodT18, RNase, dNTP and MLV enzymes, 5X buffer (GE Healthcare Life Sciences, Chalfont, UK) and $10 \mu \mathrm{l}$ was used to synthesize cDNA under the conditions of $37^{\circ} \mathrm{C}$ for $120 \mathrm{~min}, 99^{\circ} \mathrm{C}$ for 
$4 \mathrm{~min}$, and $4^{\circ} \mathrm{C}$ for $3 \mathrm{~min}$. Expression of c-Kit, stem cell factor (SCF), glial cell-derived neurotrophic factor (GDNF), Transient receptor potential cation channel subfamily $\mathrm{V}$ member 1 (TRPV1) and nitric oxide synthase (NOS; Tiangen Biotech Co., Ltd., Beijing, China) was amplified through RT-PCR and compared to GAPDH gene expression (Tiangen Biotech Co., Ltd.). cDNA $(2 \mu \mathrm{l})$ was mixed with $1 \mu \mathrm{l}$ of each primer $(10 \mu \mathrm{M})$ and $16 \mu \mathrm{l}$ DNase-free water in a PCR premix tube (AccuPower PCR PreMix; Bioneer Corporation, Daejeon, Korea), and PCR was performed in an automatic thermocycler (T100, Bio-Rad, Hercules, CA, USA) for 40 cycles of $94^{\circ} \mathrm{C}$ for $5 \mathrm{~min}, 58^{\circ} \mathrm{C}$ for $30 \mathrm{sec}$, and $72^{\circ} \mathrm{C}$ for $90 \mathrm{sec}$, followed by a $10 \mathrm{~min}$ cycle at $95^{\circ} \mathrm{C}$. The primers were as follows: Forward: 5'-AGA CCG AAC GCA ACT T-3' and reverse, 5'-GGT GCC ATC CAC TTC A-3' for c-Kit; forward, 5'-AAA CTG GTG GCG AAT C-3'; reverse, 5'-CAC GGG TAG CAA GAA C-3') for SCF; forward, 5'-TTT TAT TCA AGC CAC CAT C-3'; reverse, 5'-AGC CCA AAC CCA AGT CA-3' for GDNF; forward, 5'-AGC GAG TTC AAA GAC CCA GA-3' and reverse, 5'-TTC TCC ACC AAG AGG GTC AC-3' for TRPV1; and forward, 5'-CCA CAT CTG GCA GGA TGA GAA-3' and reverse, 5'-AGG CAC AGA ACT GAG GGT ACA-3' for NOS (Tiangen Biotech Co., Ltd., Beijing, China); and forward, 5'-CGG AGT CAA CGG ATT TGG TC-3' and reverse, 5'-AGC CTT CTC CAT GGT CGT GA-3' for GAPDH gene expression (Tiangen Biotech Co., Ltd.). Subsequently, 2\% agarose gels in $1 \mathrm{X}$ Tris-acetate-EDTA were used to assess the amplification of genes by PCR (15).

Western blot analysis. Following the extraction of tissue protein with RIPA lysate, the total protein concentration of each group was homogenized with ice-cold radioimmunoprecipitation assay (RIPA; Easybio, Beijing, China) buffer in ice-cold PBS, then the extraction was centrifuged at $13,000 \times \mathrm{g}$ for $30 \mathrm{~min}$ at $4^{\circ} \mathrm{C}$. The protein $(30 \mu \mathrm{g})$ was determined using an ultraviolet spectrophotometer, and the concentrations were adjusted to the same level. Protein samples were separated by $10-12 \%$ SDS-PAGE (Schleicher and Schuell, Keene, NH, USA) for $4 \mathrm{~h}$ and transferred to nitrocellulose membranes. Membranes were sealed for $3 \mathrm{~h}$ in sealing fluid, washed 3 times with Tris-buffered saine (TBS; Easybio, Beijing, China) and incubated with primary antibodies against c-Kit (cat no. ab62154, Abcam, Cambridge, MA, USA), SCF (cat no. ab83866; Abcam), TRPV1 (cat no. ACC-030, Alomone; Beijing, China), GDNF (cat no. ab18956; Abcam), NOS (cat no. sc-49058; Santa Cruz Biotechnology, Inc., Dallas, TX, USA) and $\beta$-actin (cat no. ab8226; Abcam) for 2 h. After washing with PBS containing $0.05 \%$ Tween 20 (PBS-T), blots were and then incubated with horseradish peroxidase-conjugated goat-anti-rabbit IgG secondary antibody (Cell Signaling Technology, Inc.) for $1 \mathrm{~h}$ at room temperature. Following washing 3 times with TBS, treatment with an ultra-sensitive light liquid on a light sensitive X-plate (cat no. BE6031, Easybio, Beijing, China), the nitrocellulose filters were developed and fixed (16). Protein expression levels of c-Kit, SCF, TRPV1, GDNF and NOS were determined, with $\beta$-actin as the reference gene.

Statistical analysis. Experimental data are presented as the mean \pm standard deviation. Differences between the mean values for individual groups were assessed with a one-way analysis of variance with Duncan's multiple range tests. $\mathrm{P}<0.05$ was considered to indicate a statistically significant difference. SAS 9.2 (SAS Institute Inc., Cary, NC, USA, 2009) was used for statistical analyses.

\section{Results}

Morphological observation of FCQS and CQS. As demonstrated in Fig. 1, the fiber gaps in FCQS increased and the structure became more relaxed, whereas the fiber gap of CQS was dense and tighter.

First black stool defecation. Following treatment with activated carbon, the duration until the first black stool defecation was highest in the control mice (192 min), as compared with $85 \mathrm{~min}$ in the normal mice (Fig. 2). Treatment with bisacodyl, which is an anti-constipation drug, decreased the duration between treatment and first black stool defecation to $99 \mathrm{~min}$. Notably, the FCQS-fed mice (117 min) exhibited a significantly shorter time than CQS-fed mice $(148 \mathrm{~min} ; \mathrm{P}<0.05)$ and control mice $(\mathrm{P}<0.01)$; however the duration exhibited by FCQS-fed mice remained longer than bisacodyl-treated and normal mice.

Defecation status. After inducing constipation, the defecation status of the mice in the different groups altered. The defecation count was highest in the normal mice, whereas the control group mice exhibited the lowest defecation count (Fig. 3). The defecation count of the FCQS group was higher than the CQS group, but remained lower than the bisacodyl group. The stool of the control mice was very dry, and CQS-treated mice also exhibited dry stool. Mice in the normal, bisacodyl and FCQS groups exhibited normal moist stool.

GI transit. On the final day of experimentation, all mice were treated with activated carbon by lavage. All the activated carbon was able to pass through the small intestine in normal mice 30 min post-treatment and this was set as $100 \%$ (Fig. 4; Table I). Activated carbon passed through the small intestine with difficulty in the control mice. The control mice exhibited a GI transit value of $37.9 \%$. Bisacodyl-treated mice exhibited a high GI transit value at $88.3 \%$. FCQS and CQS-treated mice also exhibited increased GI transit compared to the control mice, and FCQS-treated mice $(73.8 \%)$ exhibited increased GI transit, as compared with CQS $(61.7 \%$; $\mathrm{P}<0.01)$.

Morphological observation of the small intestine. In normal mice, the small intestinal villi were orderly, and the thicknesses of the small intestinal wall was homogeneous (Fig. 5). The villi of control mice were injured and broken, and the thickness of the small intestinal wall was heterogeneous. The small intestinal villi of bisacodyl-treated mice exhibited minimal damage and the villi of CQS and FCQS-treated mice exhibited more severe injury than bisacodyl-treated mice. CQS-treated mice exhibited more severe intestinal villi damage than FCQS-treated mice.

Serum MTL, ET-1, VIP and AchE levels. MTL, ET-1, VIP and AchE levels in the serum were highest in the normal mice (Table II), whereas the levels were lowest in control mice $(\mathrm{P}<0.05)$. Serum levels from bisacodyl-treated mice were 


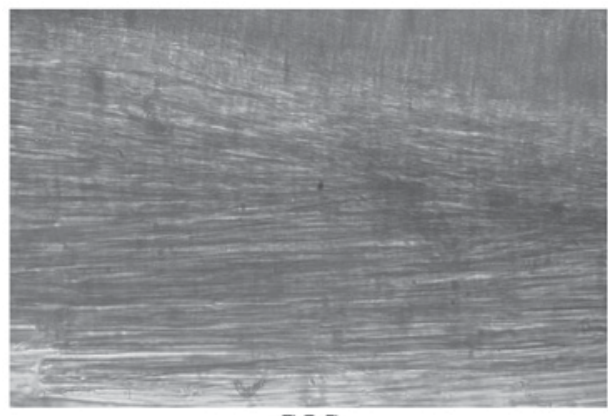

CQS

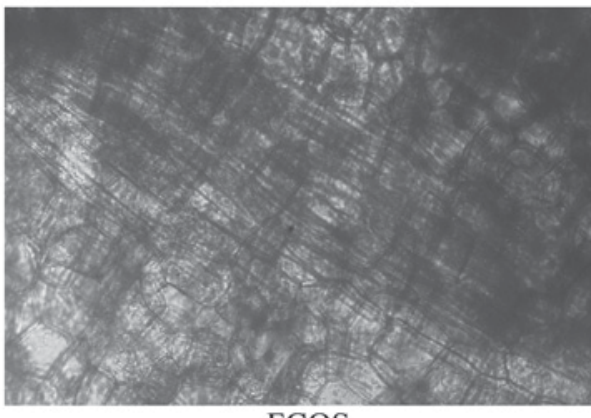

FCQS

Figure 1. Morphologic observation of fibers of fermented and fresh Chimonobambusa quadrangularis shoots (magnification, x20).

similar to those in normal mice and were higher than CQS and FCQS-fed mice. Notably, respective FCQS and CQS treatment increased these levels compared with the control mice $(\mathrm{P}<0.05)$, and fermentation further increased the levels of MTL, ET-1, VIP and AchE compared with the CQS-fed mice.

Expression levels of c-Kit and SCF. c-Kit and SCF expression levels in the small intestine of mice were determined by RT-PCR and western blotting (Fig. 6). c-Kit and SCF mRNA and protein expression levels were highest in the normal mice, whereas the control mice exhibited the lowest levels of c-Kit and SCF. Expression levels of bisacodyl-treated mice were higher than all other groups, with the exception of the normal group. FCQS-treated mice exhibited increased expression levels, as compared with the control $(\mathrm{P}<0.01)$ and $\mathrm{CQS}$-treated mice $(\mathrm{P}<0.05)$.

Expression levels of TRPVI, GDNF and NOS. TRPV1, GDNF and NOS are enteric nerve-related genes (16). FCQS was able to increase GDNF mRNA and protein levels, and decrease TRPV1 and NOS levels, as compared with the control mice $(\mathrm{P}<0.01)$ and CQS-treated mice $(\mathrm{P}<0.05$; Fig. 7). TRPV1, GDNF and NOS mRNA and protein expression levels in FCQS-treated mice were similar to those exhibited by normal and bisacodyl-treated mice.

\section{Discussion}

Constipation can damage the intestinal wall, including shortening and fracturing of the villi, affecting normal absorption and defecation (11). As a result, constipation has a notable influence on the intestine. It has previously been demonstrated that the increased fiber gap of FCQS facilitates the improved penetration of water to the fibers and increases its absorbency and water-holding capacity, which increases the volume of excrement that stimulates intestinal peristalsis (17). Furthermore, increased water content in excrement may prevent dry excrement, which increases bowel movements(18). Previous research has demonstrated that fermentation can significantly improve the water-holding ability of bamboo (10), which was confirmed in the present study. Therefore, the influence of fermentation on FCQS fiber may promote defecation and effectively relieve constipation.

Patients with constipation have difficulty defecating, and their frequency is lower than that of individuals with normal

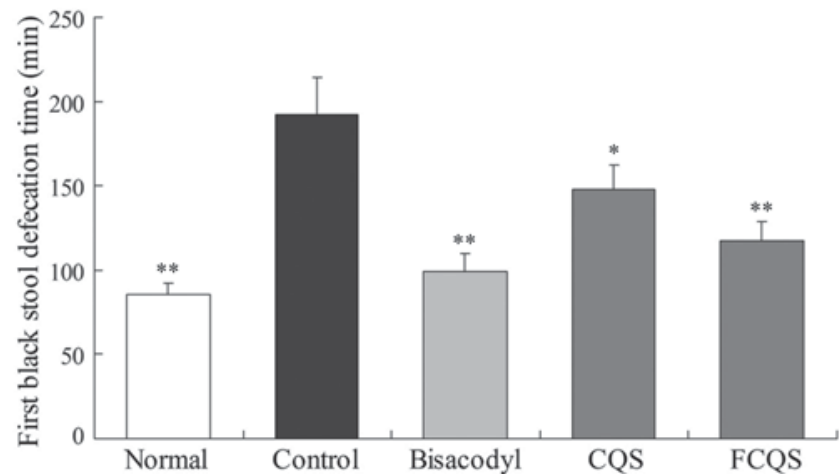

Figure 2. First black stool defecation time of mice following treatment with activated carbon by gavage. ${ }^{*} \mathrm{P}<0.05$ and ${ }^{* *} \mathrm{P}<0.01$ vs. the control group (determined by Duncan's multiple range test).

GI function and transit. A mouse constipation model may be used to simulate human constipation, and how long until mice can discharge black excrement produced by activated carbon in the state of constipation is used as the standard to measure the degree of constipation (17). The results of the present study demonstrated that the duration between treatment and the first black stool defecation in the FCQS group was significantly shorter than that of the CQS group, indicating that FCQS may be more effective at promoting intestinal health and countering constipation.

The most characteristic representation of constipation is difficulty defecating with low volumes and dry grains due to lack of water (7). Observation of the excrement of experimental mice in the present study demonstrated that, after constipation induced by activated carbon, the amount of stools passed by the control group was markedly decreased, whereas the effects of bisacodyl, CQS and FCQS were preferable, compared with normal square bamboo. These findings demonstrated that CQS is a suitable and effective food for relieving constipation, and fermentation may improve its efficacy.

Distance traveled and GI transit time of activated carbon are key indicators used to measure intestinal function, which affects the degree of constipation. Increased distance and GI transit time indicate lower degrees of constipation (19). The mouse constipation model used in the present study indicated that the intestinal activity varied and the GI transit time of activated carbon in the normal and control groups differed significantly. CQS was able to significantly relieve 


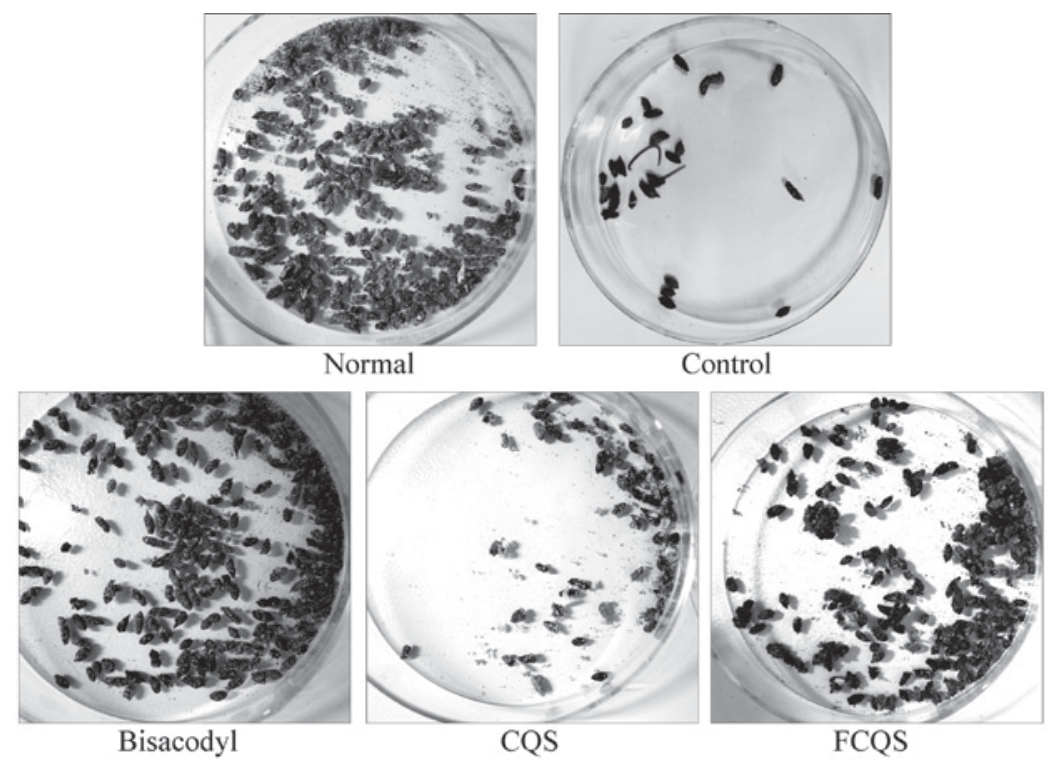

Figure 3. Dejection states of mice following treatment with constipation.

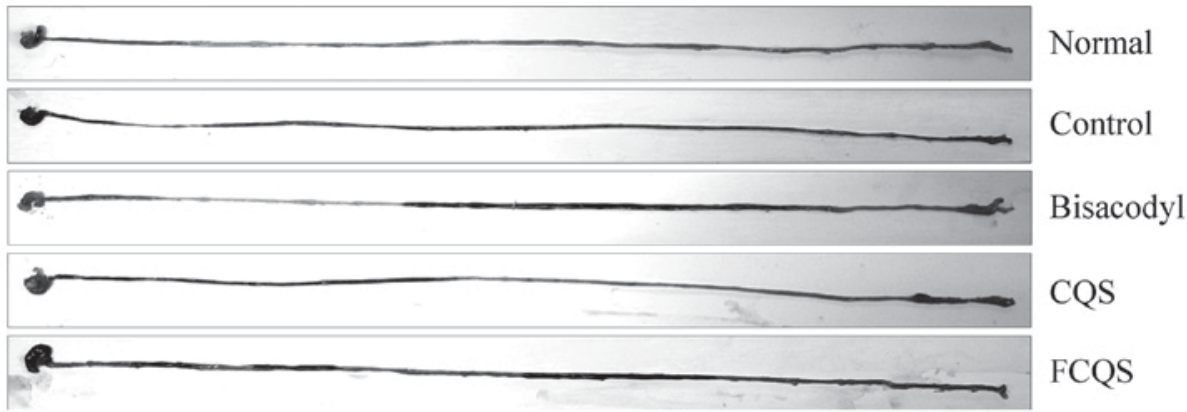

Figure 4. Propel state of small intestine in activated carbon induce constipation mice.

constipation, markedly improving the GI transit time of activated carbon in the intestine. Notably, FCQS had an superior effect on easing constipation, as compared with CQS. Furthermore, the results of the present study indicated that the effect of FCQS on constipation is similar to that of bisacodyl, which was demonstrated to be superior to the effect of fresh CQS.

MTL is a type of GI hormone that stimulates the secretion of pepsin and promotes intestinal peristalsis, which is required for normal physiological intestinal activity and defecation (20). Endothelin ensures the tension of vessels, maintaining a normal cardiovascular system and avoiding other diseases (cardiovascular disease, hypertension) caused by constipation (21). ET-1 is a key factor that regulates cardiovascular function, promoting the normal contraction and dilation of blood vessels and relieving the abnormal contraction of blood vessels caused by constipation (22). VIP relaxes smooth muscles, promoting the dilation of blood vessels, increasing the production of intestinal secretions, and stimulating intestinal peristalsis. A previous study has demonstrated that a decrease in the secretion of VIP may directly lead to constipation (23). AchE modulates intestinal contraction, promotes the secretion of mucus, and promotes defecation by enhancing intestinal contraction and the secretion of mucus, which may help to avoid constipation (24). It has been demonstrated that the levels of MTL, ET-1, VIP and AchE in mouse serum decrease with the degree of constipation (19). In the present study, compared with the control group, FCQS was able to significantly increase the levels of MTL, ET-1, VIP and AchE, and the effect was greater than that of the fresh CQS group.

A previous study demonstrated that c-Kit is expressed in the smooth muscles of mice intestines; therefore, blocking the function of c-Kit may lead to severe intestinal dysfunction and intestinal obstruction. c-Kit and SCF are interdependent, thus they are able to promote each other, therefore any decline in the expression levels of c-Kit and SCF in the intestine may cause constipation (25).

After binding with its ligand, TRPV1 opens cell passages and releases a large number of neuropeptides, excitatory amino acids and GI peptides, which causes increased intestinal sensitivity and movement disorders, leading to constipation (26). GDNF regulates the growth and development of nerve cells, ensuring the protection and repair of damaged nerves. Exogenous GDNF significantly improves intestinal function and relieves constipation (27). NOS has an important role in the intestinal tract. For example, NOS and AchE maintain the balance of intestinal movements. 
Table I. Effects of samples on gastrointestinal (GI) transit in mouse model of activated carbon-induced constipation.

\begin{tabular}{|c|c|c|c|c|c|}
\hline Variable & Normal & Control & Bisacodyl & CQS & FCQS \\
\hline Small intestine length $(\mathrm{cm})$ & $48.3 \pm 2.2^{\mathrm{a}}$ & $47.8 \pm 3.2^{\mathrm{a}}$ & $47.9 \pm 1.9^{\mathrm{a}}$ & $47.5 \pm 2.5^{\mathrm{a}}$ & $47.7 \pm 2.6^{\mathrm{a}}$ \\
\hline Distance traveled $(\mathrm{cm})$ & $48.3 \pm 2.2^{\mathrm{a}}$ & $18.1 \pm 3.9^{\mathrm{e}}$ & $42.3 \pm 2.1^{\mathrm{b}}$ & $29.3 \pm 2.2^{\mathrm{d}}$ & $35.2 \pm 1.8^{\mathrm{c}}$ \\
\hline GI transit $(\%)$ & $100.0 \pm 0.0^{\mathrm{a}}$ & $37.9 \pm 5.3^{\mathrm{e}}$ & $88.3 \pm 3.1^{\mathrm{b}}$ & $61.7 \pm 4.0^{\mathrm{d}}$ & $73.8 \pm 3.3^{c}$ \\
\hline
\end{tabular}

${ }^{\mathrm{a}-\mathrm{e}}$ Mean values with different letters in the same column are significantly different $(\mathrm{P}<0.05)$, as determined by Duncan's multiple range test. GI, gastrointestinal; CQS, Chimonobambusa quadrangularis shoot; FCQS, fermented Chimonobambusa quadrangularis shoot.

Table II. Effect of various samples on serum MTL, ET-1, VIP and AchE levels in a mouse model of activated carbon-induced constipation.

\begin{tabular}{|c|c|c|c|c|c|}
\hline Level (pg/ml) & Normal & Control & Bisacodyl & CQS & FCQS \\
\hline MTL & $189.3 \pm 23.6^{\mathrm{a}}$ & $89.3 \pm 10.7^{\mathrm{e}}$ & $162.4 \pm 17.9^{b}$ & $125.2 \pm 14.6^{\mathrm{d}}$ & $149.8 \pm 15.2^{c}$ \\
\hline ET-1 & $20.1 \pm 1.1^{\mathrm{a}}$ & $8.2 \pm 0.9^{\mathrm{e}}$ & $18.2 \pm 0.5^{\mathrm{b}}$ & $11.0 \pm 0.7^{\mathrm{d}}$ & $15.2 \pm 0.8^{c}$ \\
\hline VIP & $61.2 \pm 4.2^{\mathrm{a}}$ & $26.7 \pm 2.8^{\mathrm{e}}$ & $51.2 \pm 1.9^{\mathrm{b}}$ & $38.9 \pm 2.7^{\mathrm{d}}$ & $44.3 \pm 1.3^{c}$ \\
\hline AchE & $37.8 \pm 1.5^{\mathrm{a}}$ & $13.5 \pm 0.4^{\mathrm{e}}$ & $30.6 \pm 0.8^{\mathrm{b}}$ & $19.3 \pm 1.2^{\mathrm{d}}$ & $26.4 \pm 1.1^{\mathrm{c}}$ \\
\hline
\end{tabular}

${ }^{\mathrm{a}-\mathrm{e}}$ Mean values with different letters in the same column are significantly different $(\mathrm{P}<0.05)$, as determined by Duncan's multiple range test. MTL, motilin; ET, endothelin; VIP, vasoactive intestinal peptide; AchE, acetylcholine enzyme; CQS, Chimonobambusa quadrangularis shoot; FCQS, fermented Chimonobambusa quadrangularis shoot.

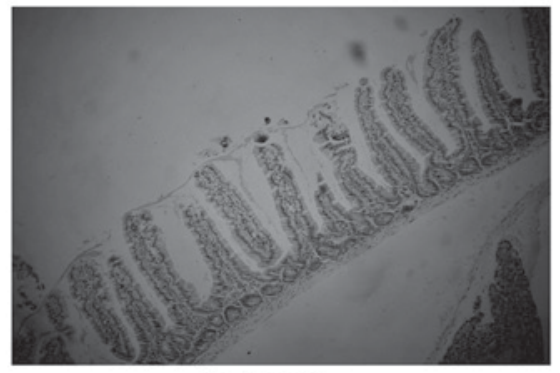

Normal

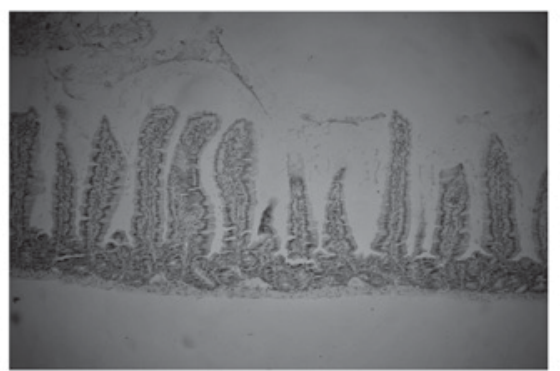

Bisacodyl

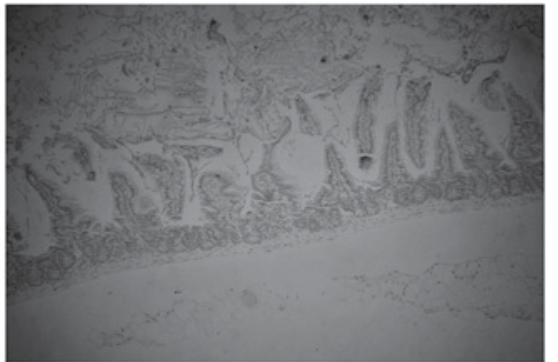

CQS

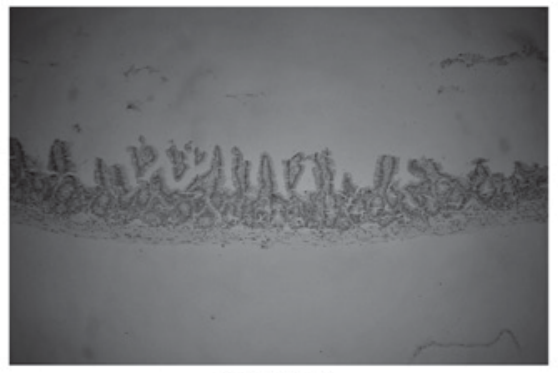

Control

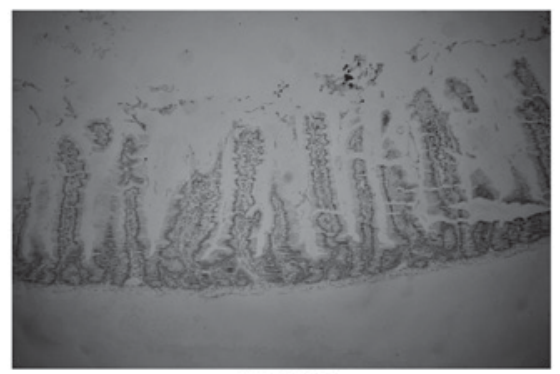

FCQS

Figure 5. Morphological observation of the small intestine in mice following hematoxylin and eosin staining (magnification, $\mathrm{x} 10$ ).

NOS inhibits the release of AchE, and NOS and VIP exhibit a close morphological relationship that is directly associated with constipation. Excessive NOS may lead to constipation and a decrease of other factors that are beneficial to the intestine (28).

The aim of the present study was to investigate whether C. quadrangularis shoot has a preventative effect against activated carbon-induced constipation and whether fermentation was able to increase this effect in mice. FCQS exhibits a higher quality of fiber compared with CQS. FCQS-fed mice exhibited an increased duration between treatment and the first black stool defecation, as compared with bisacodyl-treated and normal mice; however FCQS-fed mice exhibited a shorter duration than CQS-fed and control mice. The dejection states of FCQS-fed mice were also similar to the bisacodyl-treated and normal mice. GI transit time was 

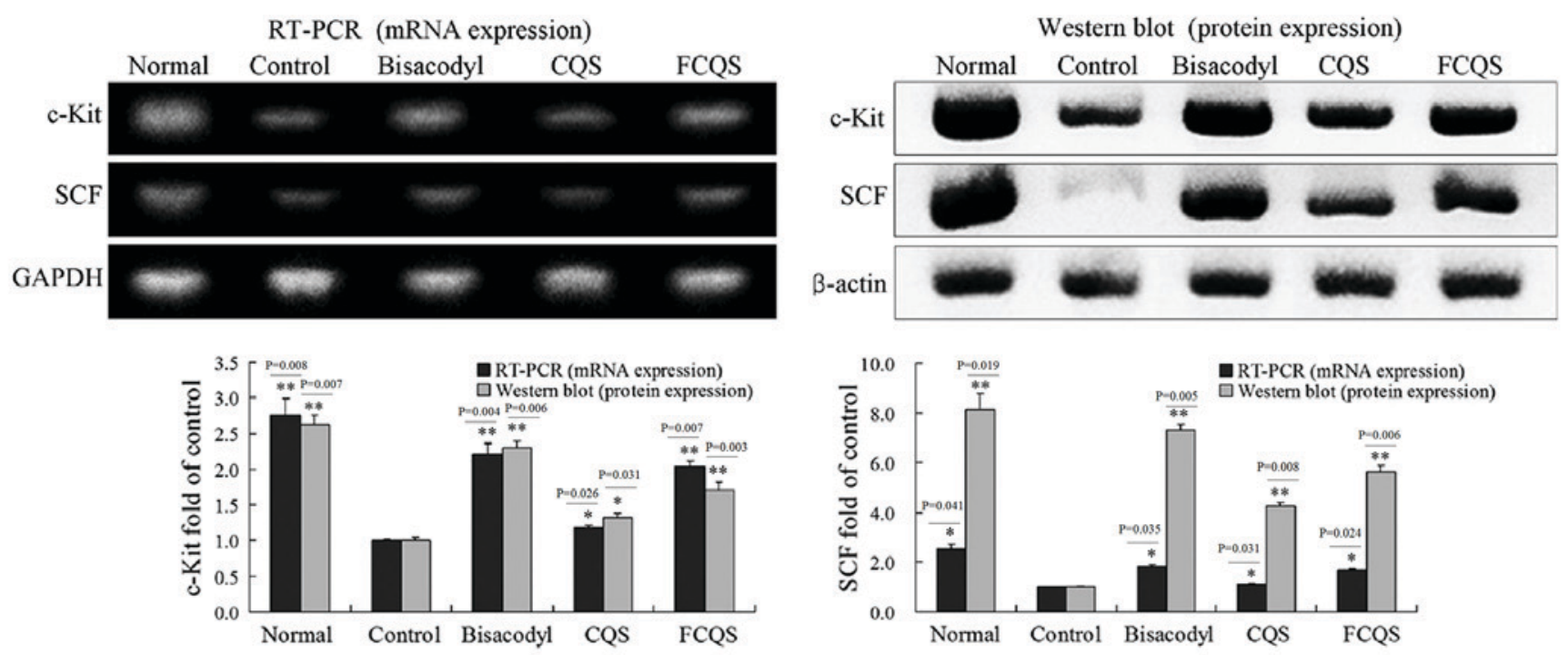

Figure 6. Effects of fermented Chimonobambusa quadrangularis shoot (FCQS) on the mRNA and protein expression of c-Kit and SCF in small intestine. Fold-ratio: gene expression/GAPDHx control numerical value (control fold ratio: 1 ). " $\mathrm{P}<0.05$ and ${ }^{* *} \mathrm{P}<0.01$ vs. control group, as determined by Duncan's multiple range test.
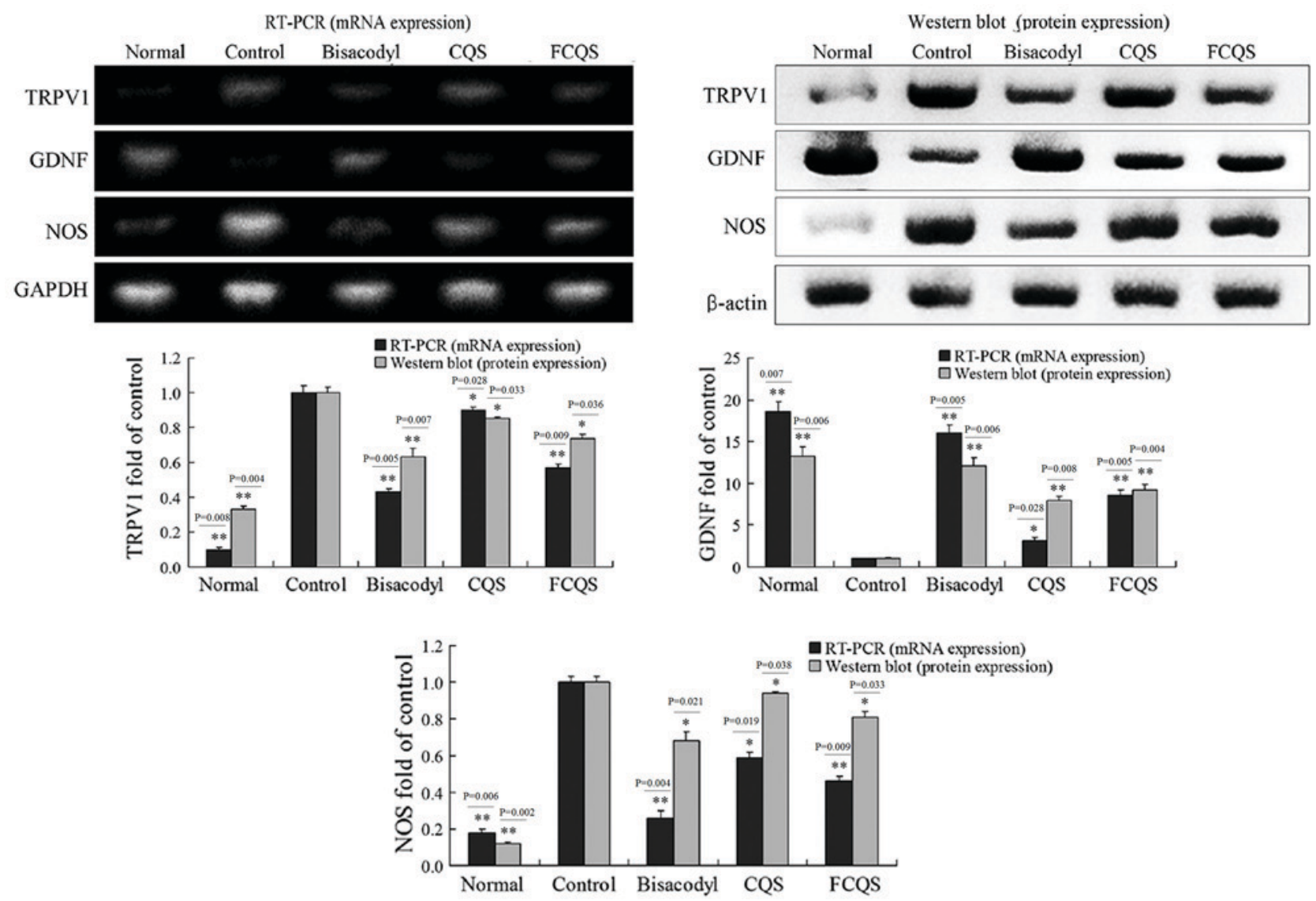

Figure 7. Effects of fermented Chimonobambusa quadrangularis shoot (FCQS) on the mRNA and protein expression of TRPV1, GDNF and NOS in small intestine. Fold-ratio: gene expression/GAPDHx control numerical value (control fold ratio: 1$)$. ${ }^{*} \mathrm{P}<0.05$ and ${ }^{* * *} \mathrm{P}<0.01$ vs. control group, as determined by Duncan's multiple range test.

increased in FCQS-fed mice, as compared with CQS-fed and control mice; however, FCQS-fed mice exhibited a GI transit time that was similar to the bisacodyl-treated and normal mice.
Numerous small intestinal injuries were detected in the control mice. Although CQS was able to decrease these injuries, FCQS exhibited a superior recovery than CQS, as determined by morphological observation. Serum MTL, 
ET-1, VIP and AchE levels of FCQS-fed mice were increased, as compared with CQS-fed and control mice. FCQS-fed mice exhibited increased mRNA expression levels of c-Kit, SCF and GDNF in the small intestine, as compared with CQS-fed and control mice; whereas TRPV1 and NOS expression levels in the small intestine of FCQS-fed mice were decreased, as compared with CQS-fed and control mice.

In conclusion, these findings suggest that FCQS exhibits a superior preventive effect on activated carbon-induced constipation in mice, as compared with CQS. Further research is required to fully elucidate the protective effects and dosage requirements for FCQS as a therapeutic strategy for the treatment of constipation.

\section{Acknowledgements}

The present research was supported by the Scientific and Technological Research Program of Chongqing Municipal Education Commission (grant no. KJ1401411), the Studio of Chongqing Urban and Rural Teacher's Overall-planning Education Research Center (grant no. JDGZS201507), Chongqing Application Development Projects (grant no. cstc2014yykfB80017), the Construction Program of Chongqing Engineering Research Center (grant no. cstc2015yfpt_gcjsyjzx0027) and the Program for Innovation Team Building at Institutions of Higher Education in Chongqing (grant no. CXTDX201601040).

\section{References}

1. Li R, Wu LR and Zhou CP: A study on the mineral nutrition composition of Chimonobambusa quadrangularis bamboo shoots. J Bamboo Res 26: 37-39, 2007.

2. Feng HY, Li M and Ma YH: Technology of harvesting processing on Chimonobambusa utilis (Keng) Keng f. World Bamboo Rattan 14: 27-28, 2006.

3. Zhang RG, Li M, Wang XQ and Liu LC: Preliminary study of the forming of special quality of Chimonobambusa utilis bamboo shoot in Nanchuan, Chongqing. World Bamboo Rattan 8: 30-33, 2010.

4. Li AP, Xie BX, Tian YF and Gu ML: Effect of fermentation on anti-nutritional factor contents and adsorption of dietary fiber for $\mathrm{Ca}^{2+}, \mathrm{Mg}^{2+}, \mathrm{Pb}^{2+}$. Food Sci Technol (Campinas) 35: 96-99, 2010.

5. Hsu HH, Leung WH and Hu GC: Treatment of irritable bowel syndrome with a novel colonic irrigation system: A pilot study. Tech Coloproctol 20: 551-557, 2016.

6. Christer R, Robinson L and Bird C: Constipation: Causes and cures. Nurs Times 99: 26-27, 2003.

7. Liu W, Liu XH, Fang XC, Zhou LK, Yang XL, Ke MY, Zhao HC, Zhang M, Xie PY, Hao JY, et al: A multicenter epidemiological investigation on outpatients with chronic constipation in Beijing area. Clin J Gastroenterol 15: 95-98, 2010.

8. Zhou HJ, Zhang QS, Shi L, Li H, Xu JY, Huang CY, Chen G and Li M: Effect of direct vat set Lactobacillus on intestinal function in mice with constipation. Food Ferment Technol 49: 26-29, 2003.

9. Wang Y, Cai DL, Yuan JY, Zhang YZ, Zhou JH and Li HQ: Effect of dietary fibers on patient with functional constipation. Wu Jing Yi Xue 25: 13-15, 2014 (In Chinese).
10. Jiang NQ, Xie BX, He G, Li AP and Xie T: Studies on intestinal peristalsis induced by fermenting bamboo-shoots dietary fiber. Acta Nutr Sinica 24: 439-440, 2002.

11. Qian Y,Zhao X and Kan J: Preventive effect of resistant starch on activated carbon-induced constipation in mice. Exp Ther Med 6: 228-232, 2013.

12. Li G, Wang Q, Qian Y, Zhou Y, Wang R and Zhao X: Component analysis of Pu-erh and its anti-constipation effects. Mol Med Rep 9: 2003-2009, 2014

13. Li GJ, Qian Y, Sun P, Feng X, Zhu K and Zhao X: Preventive effect of polysaccharide of Larimichthys Crocea swimming bladder on activated carbon-induced constipation in mice. J Korean Soc Appl Biol Chem 57: 167-172, 2014.

14. Chen LH, Song JL, Qian Y, Zhao X, Suo HY and Li J: Increased preventive effect on colon carcinogenesis by use of resistant starch (RS3) as the carrier for polysaccharide of Larimichthys crocea swimming bladder. Int J Mol Sci 15: 817-829, 2014.

15. Zhao X, Wang Q, Li GJ, Chen F, Qian Y and Wang R: In vitro antioxidant, anti-mutagenic, anti-cancer and anti-angiogenic effects of Chinese Bowl tea. J Funct Food 7: 590-598, 2014.

16. Zhao X, Suo HY, Qian Y, Li GJ, Liu ZH and Li J: Therapeutic effects of Lactobacillus casei Qian treatment in activated carboninduced constipated mice. Mol Med Rep 12: 3191-3199, 2015.

17. Wu LR, Gao GB, Bai RH, Shao Q and Li R: Research and application of dietary fiber from bamboo shoots. J Bamboo Res 29: $1-5+33,2010$

18. Whitehead WE, Palsson OS and Simrén M: Biomarkers to distinguish functional constipation from irritable bowel syndrome with constipation. Neurogastroenterol Motil 28: 783-792, 2016.

19. Qian Y, Suo H, Du M, Zhao X, Li J, Li GJ, Song JL and Liu Z: Preventive effect of Lactobacillus fermentum Lee on activated carbon-induced constipation in mice. Exp Ther Med 9: 272-278, 2015.

20. Liu Y, Zhao XR, Wang R, Qiu GQ and Zhang M: Effect of Zhizhuwan on gastrointestinal peptide concentrations in plasma of diabetic gastroenteropathy with constipation patients. Zhongguo Zhong Yao Za Zhi 33: 2966-2968, 2008 (In Chinese).

21. Zhao X, Qian Y, Suo HY, Du MY, Li GJ, Liu ZH, et al: Preventive effect of Lactobacillus fermentum Zhao on activated carboninduced constipation in mice. J Nutr Sci Vitaminol 61, 131-137, 2015.

22. Song HL, Tian FS, Qiao P and Duan HB: Effects of Sanhuang tablet on plasma ET and NO levels in patients with diabetic constipation. Chinese J Tradit Med Sci Technol 17: 285-286, 2010.

23. King SK, Sutcliffe JR, Ong SY, Lee M, Koh TL, Wong SQ, Farmer PJ, Peck CJ, Stanton MP, Keck J, et al: Substance P and vasoactive intestinal peptide are reduced in right transverse colon in pediatric slow-transit constipation. Neurogastroenterol Motil 22: 883-892, 2010.

24. Suo H,Zhao X, Qian Y, Li G, Liu Z, Xie J and Li J: Therapeutic effect of activated carbon-induced constipation mice with Lactobacillus fermentum Suo on treatment. Int J Mol Sci 15: 21875-21895, 2014.

25. Brading AF and McCloskey KD: Mechanisms of disease: Specialized interstitial cells of the urinary tract-An assessment of current knowledge. Nat Clin Pract Urol 2: 546-554, 2005.

26. Geppetti $P$ and Trevisani M: Activation and sensitisation of the vanilloid receptor: Role in gastrointestinal inflammation and function. Br J Pharmacol 141: 1313-1320, 2004.

27. Xu GP, Fan YH and Lv B: Advances in understanding the role of neurotrophins in physiological and pathological processes in the intestinal tract. World Chinese J Digestol 18: 2884-2888, 2010.

28. Tomita R, Igarashi S, Fujisaki S and Tanjoh K: The effects of neurotensin in the colon of patients with slow transit constipation. Hepatogastroenterology 54: 1662-1666, 2007. 